\title{
High expression of monocarboxylate transporter 4 predicts poor prognosis in patients with lung adenocarcinoma
}

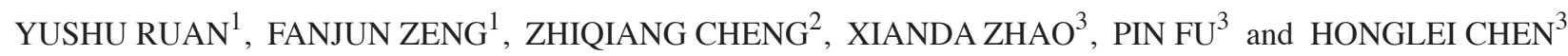 \\ ${ }^{1}$ Department of Respiratory Medicine, First College of Clinical Medical Sciences, China Three Gorges University, \\ Yichang, Hubei 443003; ${ }^{2}$ Department of Pathology, Shenzhen People's Hospital, Shenzhen, Guangdong 518020; \\ ${ }^{3}$ Department of Pathology, School of Basic Medical Science, Wuhan University, Wuhan, Hubei 430071, P.R. China
}

Received March 3, 2016; Accepted March 17, 2017

DOI: $10.3892 / \mathrm{ol} .2017 .6964$

\begin{abstract}
Monocarboxylate transporter 4 (MCT-4) serves a key function in transporting lactate across the plasma membrane in various types of human cancer. Evidence indicates that MCT-4 expression is associated with non-small cell lung cancer; however, the distribution and clinical significance of MCT-4 in the lung adenocarcinoma (AC) subtype remain unknown. Thus, the aim of the present study was to explore the clinicopathological significance and prognostic values of MCT-4 expression in lung AC. Quantum dots-based immunofluorescence histochemistry was performed to observe the expression of MCT-4 in 146 specimens of lung AC and corresponding normal lung tissues. MCT-4 protein and mRNA were detected by western blotting and reverse transcription-quantitative polymerase chain reaction from 30 fresh samples of lung AC and corresponding normal lung tissues. Of the 146 samples, 25 (17.1\%) exhibited high and $121(82.9 \%)$ exhibited low MCT-4 expression. MCT-4, at the protein and mRNA level, was significantly increased in tumor specimens compared with corresponding normal lung tissue $(\mathrm{P}<0.05)$. MCT-4 protein expression was significantly associated with depth of invasion $(\mathrm{P}=0.034)$. A survival curve analysis indicated that high MCT-4 expression in lung AC was associated with a decreased overall survival rate $(\mathrm{P}=0.001)$. Multivariate analysis demonstrated that high MCT-4 level was an independent prognostic factor (hazard ratio, 3.192; 95\% confidence interval, 1.804-5.646; $\mathrm{P}=0.001$ ) for patients with lung $\mathrm{AC}$.
\end{abstract}

Correspondence to: Dr Yushu Ruan, Department of Respiratory Medicine, First College of Clinical Medical Sciences, China Three Gorges University, 183 Yiling Avenue, Yichang, Hubei 443003, P.R. China

E-mail: ruanyumei2003@163.com

Dr Honglei Chen, Department of Pathology, School of Basic Medical Science, Wuhan University, 185 Donghu Road, Wuhan, Hubei 430071, P.R. China

E-mail: hl-chen@whu.edu.cn

Key words: lung adenocarcinoma, monocarboxylate transporter 4, tumor progression, prognosis, quantum dots
The results have demonstrated that high MCT- 4 expression is significantly associated with the poor prognosis and disease progression of patients with lung AC. Therefore, MCT-4 may be a candidate therapeutic target in lung $\mathrm{AC}$.

\section{Introduction}

Lung cancer is one of the most fatal types of cancer in developed countries; $>25 \%$ of cancer-associated mortalities are caused by lung cancer (1). Non-small cell lung cancer (NSCLC) constitutes $\sim 80 \%$ of lung cancer cases. Lung adenocarcinoma (AC) is the main histological subtype of NSCLC and its incidence rate is rising (2). Even in cases where patients undergo complete resection by lymph node dissection, there is a $30-40 \%$ chance of the patient succumbing to recurrent disease, and the 5-year survival rate for lung cancer is just $15.7 \%(3,4)$. In order to identify the most effective clinical strategies, it is necessary to predict which patients have a high risk of recurrence.

Certain defects, particularly the inclusion of bronchioloalveolar carcinoma within AC subtypes, were present in the 2004 World Health Organization classification system for lung AC (5). To overcome these issues, a new system was produced by the International Association for the Study of Lung Cancer, the American Thoracic Society and the European Respiratory Society (IASLC/ATS/ERS) in 2011. The new International Multidisciplinary Lung Adenocarcinoma Classification was published in the Journal of Thoracic Oncology, the official journal of IASLC (5). This classification is intended to support clinical practice as well as research investigation and clinical trials (5). Most importantly, it may offer prognostic information, such as grading lung ACs according to histological architecture, which results in significant differences in prognoses (6). In the present study, the new classification system was used for introducing the research results.

Tumors are composed of cancer cells and tumor stroma that are disparate but interactive, just as normal tissue is composed of parenchymal cells and surrounding supporting cells. The extracellular matrix, vascular endothelial cells, immune cells, inflammatory cells and cancer-associated fibroblasts are constituents of tumor stroma (7-9). Cancer cells are typically hyperproliferative, exhibit a high rate of glycolysis and are resistant to apoptosis when compared with the surrounding, 
normal cells. Glycolysis is a part of energy metabolism and includes lactic acid fermentation, of which the end product is lactate (10). In mammalian cells, it is the most important step to obtain adenosine triphosphate, including in cancer tissue. Tumor cells also undergo proton efflux to prevent apoptosis due to acidosis through $\mathrm{pH}$ regulators, including proton pumps, sodium-proton exchangers, bicarbonate transporters and monocarboxylate transporters (MCTs), which are previously demonstrated to be highly expressed in HeLa tumor cells (11).

MCTs mediate the transport of various monocarboxylates, including lactate, pyruvate and ketones, across cell membranes. The transporter expression and function of MCTs in various types of cancer has yet to be comprehensively studied, although their function is well-characterized in normal tissue (12). MCTs may serve a crucial function in tumor biology according to recent observations (12). The MCT family includes 14 members. Of these, only MCT 1-4 facilitate the proton-coupled transport of lactate (13-17); although these proteins are all transmembrane symporters, their specific distributions and functions differ. MCT-1 and MCT-4 are situated in the cell membrane. Utilizing the $\mathrm{pH}$ gradient, MCT-1 catalyzes the import and export of lactate, whereas MCT-4 only exports lactate (13). MCT-2 is associated with importing pyruvate following lactate oxidation, and is expressed in the mitochondrial membrane $(18,19)$. MCT-3 is restricted to the choroid plexus and retinal pigment epithelia, and can only export lactate (12).

MCT-4 is overexpressed in cells with upregulated glycolysis, including in tumors $(18,20,21)$, white blood cells $(13,16)$ and white muscle (22). A number of previous studies have evaluated the immunohistochemical expression and prognostic significances of MCT- 4 in cancer, including gastrointestinal $(23,24)$, breast $(23,25)$, ovarian $(23)$, lung $(23)$, oral $(26)$, prostate (27) cancer. However, the clinical relevance of MCT-4 expression to lung AC has yet to be elucidated. Therefore, the present study aimed to clarify the predictive role of MCT-4 expression level for the overall survival (OS) of patients with lung $\mathrm{AC}$, and to further assess its clinicopathological significance, thus potentially identifying a novel potential therapeutic target for the treatment of patients with lung AC.

\section{Materials and methods}

Patients and follow-up. A total of 146 lung AC patients, for which resected tumor and corresponding normal lung tissues were available, were retrospectively recruited from the Department of Pathology, Zhongnan Hospital of Wuhan University (Wuhan, China). Patients with lung AC were diagnosed between July 2004 to December 2011. All these 146 patients were treated with lobectomy of lung AC, prior to administration of chemotherapy or radiotherapy, and classified according to the 7 th edition TNM classification by IASLC (2009) (28). The tumor specimens comprised 131 cases of invasive $\mathrm{AC}$ and 15 of variant invasive $\mathrm{AC}$, in accordance with the 2011 International Association for the Study of Lung Cancer/American Thoracic Society/European Respiratory Society system (5). Basic clinicopathological information is presented in Table I. Additionally, fresh lung AC and corresponding normal lung tissue were harvested during resection from another 30 patients from Zhongnan Hospital of Wuhan
Table I. Patient clinicopathological characteristics.

\begin{tabular}{|c|c|}
\hline Characteristics & Value \\
\hline Total, n & 146 \\
\hline Age, median years (range) & $59(20-84)$ \\
\hline \multicolumn{2}{|l|}{ Gender, n (\%) } \\
\hline Male & $80(54.8)$ \\
\hline Female & $66(45.2)$ \\
\hline \multicolumn{2}{|l|}{ Survival status, n (\%) } \\
\hline Alive & $81(55.5)$ \\
\hline Deceased & $65(44.5)$ \\
\hline \multicolumn{2}{|l|}{ Invasion depth, n (\%) } \\
\hline $\mathrm{T} 1$ & $28(19.2)$ \\
\hline $\mathrm{T} 2$ & $101(69.2)$ \\
\hline T3 & $12(8.2)$ \\
\hline $\mathrm{T} 4$ & $5(3.4)$ \\
\hline \multicolumn{2}{|c|}{ Lymph node metastasis, n (\%) } \\
\hline No & $86(58.9)$ \\
\hline N1 & $38(26.0)$ \\
\hline $\mathrm{N} 2$ & $10(6.8)$ \\
\hline N3 & $1(0.7)$ \\
\hline NX & $11(7.5)$ \\
\hline \multicolumn{2}{|l|}{ Distant metastasis, $\mathrm{n}(\%)$} \\
\hline M0 & $143(97.9)$ \\
\hline M1 & $3(2.1)$ \\
\hline \multicolumn{2}{|l|}{ TNM stage, $\mathrm{n}(\%$ total $)$} \\
\hline $\mathrm{IA} / \mathrm{B}$ & $25 / 18(29.5)$ \\
\hline IIA/B & $50 / 29(54.1)$ \\
\hline IIIA/B & $18 / 3(14.4)$ \\
\hline IV & $3(2.1)$ \\
\hline \multicolumn{2}{|l|}{ Histological type, n (\%) } \\
\hline Invasive $\mathrm{AC}$ & $131(89.7)$ \\
\hline Adherent & $16(11.0)$ \\
\hline Acinar & $58(39.7)$ \\
\hline Papillary & $24(16.4)$ \\
\hline Micropapillary & $6(4.1)$ \\
\hline Solid & $27(18.5)$ \\
\hline Variant AC & $15(10.3)$ \\
\hline Mucinous & $7(4.8)$ \\
\hline Colloid & $5(3.4)$ \\
\hline Lepidic & $1(0.7)$ \\
\hline Intestinal & $2(1.4)$ \\
\hline
\end{tabular}

$\mathrm{AC}$, adenocarcinoma.

University, and stored at $-80^{\circ} \mathrm{C}$ for protein and total RNA extraction. These fresh tissues were obtained between June 2014 and June 2017 by lobectomy prior to the administration of chemotherapy or radiotherapy, and included 8 cases of lepidic predominant, 11 of acinar predominant, 3 of micropapillary predominant and 8 of papillary predominant lung AC. In the present study, the 30 patients were composed of 18 males and 12 females (mean age, 56; age range, 35-78). The present 
study was permitted by the Institute Research Medical Ethics Committee of the Medical College of Wuhan University, and informed consent was obtained from each patient.

Follow-up began on the date of surgery and ended in August 2012. OS time was defined as the period of time from initial diagnosis to the date of the last follow-up or patient mortality. Patients who succumbed to other diseases or unexpected events were excluded from the study.

Tissue microarray (TMA) construction. Two separate TMAs were constructed using technology and a TMA instrument from Guilin Fanpu Biotechnology, Inc. (Guilin, China). Each of the TMAs contained 146 lung specimens, including 73 tumor and 73 corresponding normal tissue specimens. The hematoxylin and eosin-stained tissue specimens were reviewed and the most representative tumor parts were selected to construct TMAs based on evaluation by two independent pathologists (H.C. and Z.C.). The methods for constructing the TMAs were as previously described (29,30). As controls, 1.5-mm diameter tumor cores were extracted from each sample and inserted into empty paraffin blocks. The blocks were cut into $4-\mu \mathrm{m}$ thick sections and used for quantum dots-based immunofluorescence histochemistry (QD-IHC) staining.

$Q D-I H C$. The QD-IHC of MCT-4 protein was performed with 4- $\mu \mathrm{m}$ sections from formalin-fixed and paraffin-embedded tissues of the two TMAs. The primary antibody was a polyclonal rabbit anti-human MCT-4 antibody [cat no. sc-50329; Santa Cruz Biotechnology, Inc., Dallas, TX, USA; dilution, 1:100 in Tris-buffered saline (TBS)]. The QD-IHC staining was performed using QD-conjugated streptavidin probes (QD-SA) with $605 \mathrm{~nm}$ emission wavelength [Wuhan Jiayuan Quantum Dot Technological Development Co., Ltd., Wuhan, China; dilution, 1:300 in 2\% bovine serum albumin (BSA, Sigma-Aldrich; Merck KGaA, Darmstadt, Germany).

The major procedures were as previously described (31): The TMAs were deparaffinized in xylene and rehydrated three times in graded alcohol washes subsequent to heating at $65^{\circ} \mathrm{C}$ for $30 \mathrm{~min}$. Antigen retrieval was performed with citric acid buffer (10 mM, pH 6.0) and a microwave for $15 \mathrm{~min}$, followed by cooling by standing at room temperature for $30 \mathrm{~min}$. TMAs were initially incubated with $2 \%$ BSA buffer at $37^{\circ} \mathrm{C}$ for $30 \mathrm{~min}$ and then with the primary antibody at $4^{\circ} \mathrm{C}$ overnight. TMAs were then washed in TBS with Tween-20 (TBS-T; $0.5 \%$ Tween, $0.1 \mathrm{M}$ Tris-base, $0.9 \% \mathrm{NaCl}$, pH 7.6) three times, for 5 min per wash. A further incubation was performed following the addition of biotinylated goat anti-rabbit secondary antibody (dilution, 1:250; cat no. ab64256; Abcam, Cambridge, UK) at $37^{\circ} \mathrm{C}$ for $30 \mathrm{~min}$. In order to conjugate QDs, antibody-bound TMAs were incubated with $2 \%$ BSA buffer at $37^{\circ} \mathrm{C}$ for $10 \mathrm{~min}$ and then in QD-SA at $37^{\circ} \mathrm{C}$ for $40 \mathrm{~min}$. The final step was washing the TMAs three times with TBS-T, for 5 min per wash, and sealing with $90 \%$ glycerin (Sigma-Aldrich; Merck $\mathrm{KGaA}$ ). The QD signal from the cells was observed with fluorescence microscopy. The positive signal was a target-specific, photo-stable bright red, whereas tissue-background autofluorescence was green. The MCT- 4 primary antibody was replaced with TBS buffer to produce controls. This protocol was strictly according to the manufacturer's protocol (Wuhan Jiayuan Quantum Dot Technological Development Co., Ltd.).
Scoring of IHC results. The results of IHC staining were independently analyzed by two experienced pathologists (H.C. and Z.C.) who were blinded to the clinical features of the patients. The evaluation was performed with a light microscope at magnification, x200 and x400 magnification; slight differences were re-evaluated with simultaneous viewing by the pathologists. Sections were scored semiquantitatively for the area of positive staining (AP) using a grading system described previously (32): 0 , no AP or AP <5\%; 1 , AP 5-25\%; 2 , AP 26-50\%; 3 , AP 51-75\%; and 4, AP $>75 \%$. In addition, the intensity of staining (IS) for MCT-4 was scored semiquantitatively as 0 (negative, no positive signal), 1 (weak, light red signal), 2 (intermediate, red signal), or 3 (strong, bright red signal). The final immunoreactivity score for MCT-4 was defined by the following formula: Intensity distribution (ID) = AP $\mathrm{x}$ IS. For determining the expression level of MCT-4 (high or low), a receiver operating characteristic (ROC) curve analysis of OS rate was performed to calculate the cutoff point.

Western blotting. Samples of lung AC and corresponding normal lung tissues (each $\sim 100 \mathrm{mg}$ ) were harvested from 30 patients, cut into pieces with surgical scissors, lysed in lysis buffer (1\% Triton X-100, $150 \mathrm{mM} \mathrm{NaCl}, 10 \mathrm{mM}$ Tris $\mathrm{pH}$ 7.4, 1 mM EDTA, 1 mM EGTA pH 8.0, 0.2 mM sodium orthovanadate, protease inhibitors) and quantified for protein concentration through the BCA Protein Assay kit (Pierce; Thermo Fisher Scientific, Inc., Waltham, MA, USA). Following $10 \%$ SDS-PAGE, $30 \mu \mathrm{g}$ protein samples were transferred to nitrocellulose membranes and incubated with primary antibodies against MCT-4 (dilution, 1:1,000 in BSA, cat no. sc-50329; Santa Cruz Biotechnology, Inc.) and monoclonal mouse anti- $\beta$-actin (dilution, 1:5,000 in BSA, cat no. A2228; Sigma-Aldrich; Merck KGaA) overnight at $4^{\circ} \mathrm{C}$. Membranes were then incubated with horseradish peroxidase-conjugated goat anti-rabbit (cat no. A0208) or goat anti-mouse (cat no. A0216) secondary antibody (both at 1:5,000; Beyotime Institute of Biotechnology, Haimen, China) for $45 \mathrm{~min}$ at $37^{\circ} \mathrm{C}$. They were visualized with Pierce enhanced chemiluminescence reagent (cat no. 34080; Pierce; Thermo Fisher Scientific, Inc.) and exposed to X-ray film in the dark. Protein bands were quantitatively analyzed using Quantity One software (version 4.62; Bio-Rad Laboratories, Inc., Hercules, CA, USA).

Reverse transcription-quantitative polymerase chain reaction (RT-qPCR). Total RNA from 30 cases of fresh lung AC and corresponding normal lung tissues was isolated with TRIzol reagent (Invitrogen; Thermo Fisher Scientific, Inc.) and reverse transcribed with the iScript cDNA Synthesis kit (Bio-Rad Laboratories, Inc.) under the following temperature conditions: $5 \mathrm{~min}$ at $25^{\circ} \mathrm{C}, 30 \mathrm{~min}$ at $42^{\circ} \mathrm{C}$, then $5 \mathrm{~min}$ at $85^{\circ} \mathrm{C}$ to terminate the reaction, according to the manufacturer's protocol. MCT-4 and $\beta$-actin mRNA expression levels were measured by qPCR using the Bio-Rad MyiQ Single Color Real-Time PCR Detection System and iQ SYBR Green SuperMix (Bio-Rad Laboratories, Inc.), according to the manufacturer's protocol. All data were analyzed by using Opticon Monitor software (version 3.1; Bio-Rad Laboratories, Inc.). All primers were synthesized by the Shanghai Sangon Biological Engineering Technology and Services Co., Ltd. (Shanghai, China) according to the published sequence for MCT-4 (NM_004207). The 


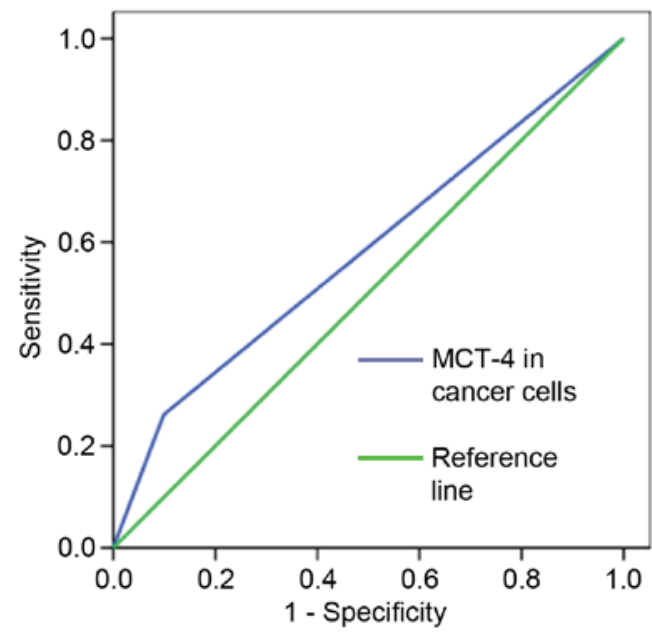

Figure 1. Receiver operating characteristic analysis of MCT-4 scores by overall survival rate of lung adenocarcinoma patients. A cut-off value for MCT-4 expression that was associated with the optimal sensitivity and specificity was defined. Area under the curve, $0.581 ; 95 \%$ CI, 0.487-0.676; $\mathrm{P}=0.092$. MCT-4, monocarboxylate transporter 4 .

primer sequences were as follows: MCT-4 forward, 5'-TGT GTGCGTGAACCGCTTT-3' and reverse, 5'-AAACCCAAC CCCGTGATGAC-3'; and $\beta$-actin forward, 5'-GGAAATCGT GCGTGACATT-3' and reverse, 5'-GACTCGTCATACTCC TGCTTG-3'. The qPCR cycling conditions were as follows: $95^{\circ} \mathrm{C}$ for $5 \mathrm{~min}$, followed by 40 cycles of $95^{\circ} \mathrm{C}$ for $10 \mathrm{sec}, 60^{\circ} \mathrm{C}$ for $15 \mathrm{sec}$ and $72^{\circ} \mathrm{C}$ for $20 \mathrm{sec}$. Quantification cycle $(\mathrm{Cq})$ values were determined for the internal control ( $\beta$-actin) and for the test gene at the same threshold level in the exponential phase of the PCR curves. Relative quantification $\left(2^{-\Delta \Delta \mathrm{Cq}}\right.$ method) was used to compare the expression level of the test genes with the internal control (33). A total of 3-4 reactions (each in triplicate) were run and the standard deviation was calculated.

Statistical analysis. All statistical analyses were estimated using SPSS 19.0 software (IBM SPSS, Armonk, NY, USA). ROC curve analysis was conducted to determine the cut-off point for high or low MCT-4 level. The $\chi^{2}$ test or Fisher's exact test were used to analyze the association between MCT-4 immunofluorescent staining and the clinicopathological parameters of patients with lung AC. OS rates were calculated using the Kaplan-Meier curve analysis and statistical significance was calculated using the log-rank test. Univariate and multivariate analyses of survival rate were performed using the Cox proportional hazards model, in order to analyze independent prognostic values. All values for MCT-4 expression detected by western blotting and RT-qPCR were expressed as the mean \pm standard error of the mean. Statistical analysis was performed using one-way ANOVA, or by Student's t-test for two groups. $\mathrm{P}<0.05$ was considered to indicate a statistically significant difference.

\section{Results}

Patient characteristics. The patients had a mean age of 59 years (range, 20-84 years), and included 80 males $(54.8 \%)$ and 66 females $(45.2 \%)$. At the end of follow-up, 81 patients $(55.5 \%)$ were alive and $65(44.5 \%)$ had succumbed to lung AC. The period of follow-up ranged from 1-96 months
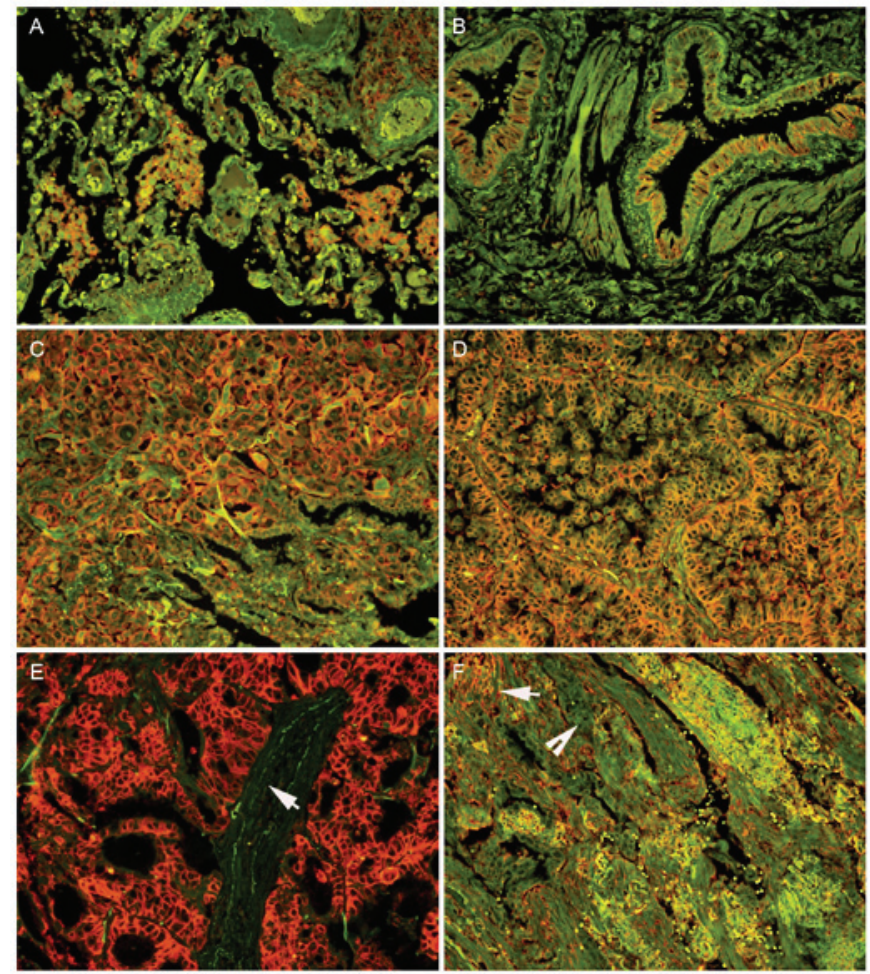

Figure 2. Expression of MCT-4 protein detected by the quantum dot immunofluorescence method in human normal lung tissues (A and B) and lung $\mathrm{AC}(\mathrm{C}-\mathrm{F})$. (A) MCT-4 protein was expressed in the cell membrane and cytoplasm of alveolar macrophages, but negative staining in the alveolar epithelial cells. (B) The bronchial epithelium exhibited MCT-4 staining. Strong MCT-4 signals were predominantly observed on the cell membrane and cytoplasm in the tumor cells of (C) solid-type and (D) papillary-type invasive AC. (E) In certain acinar-type AC cases, stromal cells (white arrow) were negative for MCT-4 staining and tumor cells exhibited strongly positive signals, whereas in other cases, (F) stromal cells (white arrow) were positive and tumor cells (white arrow head) were negative for MCT-4 staining. Magnification, x200. MCT-4, monocarboxylate transporter 4; AC, adenocarcinoma.

(mean, 41 months). With regard to the depth of invasion (T), 28 patients $(19.2 \%)$ were $\mathrm{T} 1,101(69.2 \%)$ were $\mathrm{T} 2,12(8.2 \%)$ were $\mathrm{T} 3$ and $5(3.4 \%)$ were $\mathrm{T} 4$. With regard to the extent of lymph node metastasis $(\mathrm{N}), 86(58.9 \%)$ patients were N0, 38 $(26.1 \%)$ were $\mathrm{N} 1,10(6.8 \%)$ were $\mathrm{N} 2,1(0.7 \%)$ was $\mathrm{N} 3$, and $11(7.5 \%)$ were Nx. Furthermore, 3 patients (2.1\%) exhibited distant metastasis (M1) whereas 143 patients (97.9\%) did not (M0). When comprehensively considering TNM stage based on these three aspects, 43 patients $(29.5 \%)$ were classified as stage I, $79(54.1 \%)$ as stage II, $21(14.4 \%)$ as stage III and $3(2.0 \%)$ as stage IV. Other clinicopathological factors are presented in detail in Table I.

Cut-off value of MCT-4 expression level. To obtain the cut-off values for high and low expression level accurately, a ROC curve analysis was performed with OS (Fig. 1). An ID score of 3.5 was determined as the cut-off score for MCT-4 expression in lung AC (an ID score $\geq 3.5$ indicated high expression and $<3.5$, low expression) according to the optimal sensitivity and specificity based on the curve.

Expression of MCT-4 in normal lung and AC tissues. The expression of MCT-4 protein was detected in the cell membrane and cytoplasm of some of the alveolar macrophages (Fig. 2A) 
Table II. Correlations between MCT-4 expression and clinicopathological parameters of lung AC.

\begin{tabular}{|c|c|c|c|c|}
\hline \multirow[b]{2}{*}{ Features } & \multirow[b]{2}{*}{$\mathrm{n}$} & \multicolumn{3}{|c|}{ Expression of MCT-4 } \\
\hline & & $\begin{array}{l}\text { Low, } \\
\mathrm{n}(\%)\end{array}$ & $\begin{array}{l}\text { High, n } \\
(\%)\end{array}$ & $\begin{array}{c}\mathrm{P}- \\
\text { value }\end{array}$ \\
\hline Gender & & & & 0.145 \\
\hline Male & 80 & $63(78.8)$ & $17(21.2)$ & \\
\hline Female & 66 & 58 (87.9) & $8(12.1)$ & \\
\hline Age, years & & & & 0.715 \\
\hline$\leq 63$ & 98 & $82(83.7)$ & $16(16.3)$ & \\
\hline$>63$ & 48 & $39(81.3)$ & $9(18.7)$ & \\
\hline Invasion depth & & & & 0.034 \\
\hline $\mathrm{T} 1 / 2$ & 129 & $110(85.3)$ & $19(14.7)$ & \\
\hline $\mathrm{T} 3 / 4$ & 17 & $11(64.7)$ & $6(35.3)$ & \\
\hline $\begin{array}{l}\text { Lymph node } \\
\text { metastasis }\end{array}$ & & & & 0.746 \\
\hline No & 86 & $72(83.7)$ & $14(16.3)$ & \\
\hline $\mathrm{N} 1 / 2 / 3 / \mathrm{X}$ & 60 & $49(81.7)$ & $11(18.3)$ & \\
\hline Distant metastasis & & & & 0.426 \\
\hline M0 & 143 & $118(82.5)$ & $25(17.5)$ & \\
\hline M1 & 3 & $3(100.0)$ & $0(0.0)$ & \\
\hline TNM stage & & & & 0.948 \\
\hline $\mathrm{I} / \mathrm{II}$ & 122 & $101(82.8)$ & $21(17.2)$ & \\
\hline III/IV & 24 & $20(83.3)$ & $4(16.7)$ & \\
\hline Histological type & & & & 0.256 \\
\hline Invasive AC & 131 & $107(81.7)$ & $24(18.3)$ & \\
\hline Variant invasive $\mathrm{AC}$ & 15 & $14(93.3)$ & $1(6.7)$ & \\
\hline
\end{tabular}

MCT-4, monocarboxylate transporter 4; AC, adenocarcinoma.

and bronchial epithelial cells (Fig. 2B), but no expression of MCT-4 protein was detected in the alveolar epithelial cells (Fig. 2A), as identified using QD-IHC. Positive MCT-4 signals were predominantly observed on the cell membrane, with weak staining also visible in the cytoplasm of the tumor cells (Fig. 2C and D). Notably, positive signals were not identified in stromal cells in a number of cases (Fig. 2E), whereas they were visible in others (Fig. 2F). A total of $25(17.1 \%)$ cases were determined to exhibit high MCT-4 expression, and 121 cases $(82.9 \%)$ exhibited low MCT-4 expression from the 146 lung AC tissues. No high MCT-4 expression (>3.5) was detected in the corresponding normal lung tissues.

Clinical significance and prognostic value of MCT-4 protein. For analyzing the effect of MCT-4 expression on tumor aggressiveness, the $\chi^{2}$ test or Fisher's exact test was used to evaluate the association between MCT-4 expression and clinicopathological features (Table II). A significant correlation was detected between high MCT-4 expression and advanced depth of invasion (T3/4 vs. T1/2; $\mathrm{P}=0.034)$. However, no significant associations were identified between MCT-4 expression levels and any other clinicopathological variables.

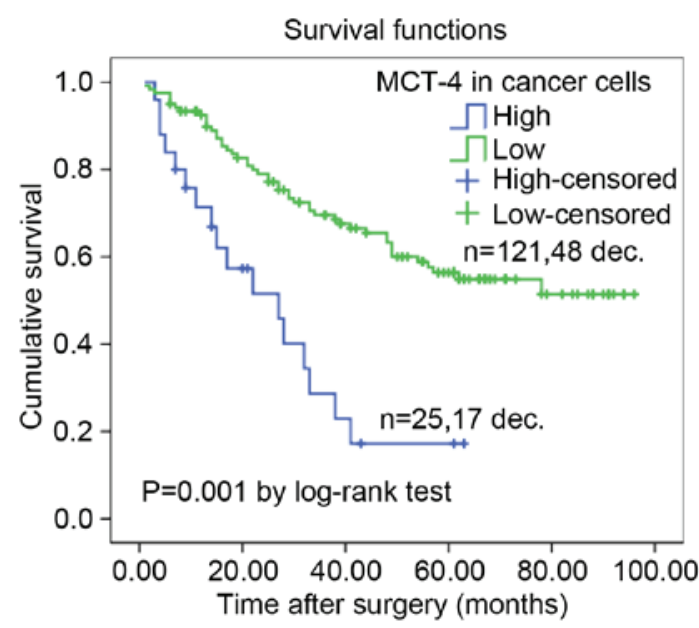

Figure 3. Cumulative survival curves of patients with lung AC. A high expression level of MCT-4 was associated with a reduced overall survival rate in patients with lung $\mathrm{AC}(\mathrm{P}=0.001$ high vs. low, log-rank test). $\mathrm{AC}$, adenocarcinoma; MCT-4, monocarboxylate transporter 4; dec., deceased.

Additionally, the Kaplan-Meier method with the log-rank test was performed to estimate a survival curve for OS rate and assess the difference in survival rate between patients with high and low MCT-4 expression levels. The mean OS time of the high MCT-4 expression group was only 27.4 months $(95 \%$ CI, 18.995-35.902 months), whereas the low MCT-4 expression level was 64.8 months (95\% CI, 58.072-71.584). After the final follow-up, the survival rate of the high MCT-4 expression group was $31.8 \%$, which was decreased compared with that of the group with low MCT-4 expression (60.3\%; Fig. 3). The survival curve indicated that high MCT-4 expression in lung AC significantly predicts a decreased likelihood of survival $(\mathrm{P}=0.001$; Fig. 3).

Furthermore, a Cox proportional hazard regression model was conducted for OS to investigate independent prognostic factors of lung AC patients. From a univariate analysis, it was identified that clinicopathological features including MCT-4 expression levels, depth of invasion, lymph node metastasis and TNM stage were significantly associated with the $\mathrm{OS}$ of lung AC patients $(\mathrm{P}=<0.001, \mathrm{P}=0.026, \mathrm{P}=0.018$ and $\mathrm{P}=0.005$, respectively; Table III). However, other clinicopathological features failed to independently predict lung $\mathrm{AC}$ prognosis (Table III). The results indicated that low MCT-4 expression diminished the risk of mortality significantly compared to high MCT-4 expression in lung AC patients. In addition, a multivariate analysis was subsequently performed. As indicated by Table III, only MCT-4 expression (HR, 3.192; 95\% CI, 1.804-5.646; $\mathrm{P}=0.001)$ and TNM stage (HR, 2.084; 95\% CI, 1.217-3.569; $\mathrm{P}=0.007)$ were statistically significant independent predictors for lung AC prognosis.

MCT-4 protein and $m R N A$ expression. MCT-4 protein expression in lung $\mathrm{AC}$ was revealed to be significantly increased based on the western blotting results $(\mathrm{P}=0.046$ compared to normal lung tissues; Fig. 4A). Additionally, MCT-4 mRNA level, as detected by RT-qPCR, was significantly higher in lung AC compared with normal lung tissue $(\mathrm{P}=0.035$; Fig. 4B). 
Table III. Cox proportional hazard models on the overall survival rate of lung AC patients.

\begin{tabular}{lcccccc}
\hline & \multicolumn{2}{c}{ Univariate analysis } & & \multicolumn{2}{c}{ Multivariate analysis } \\
\cline { 2 - 3 } Factor & P-value & HR $(95 \%$ CI $)$ & & P-value & HR (95\% CI) \\
\hline Gender (male vs. female) & 0.983 & $1.005(0.616-1.640)$ & & 0.855 & $0.922(0.386-2.202)$ \\
Age, years (<63 vs. $\geq 63)$ & 0.055 & $0.618(0.378-1.010)$ & & 0.115 & $2.287(0.817-6.402)$ \\
MCT-4 expression (low vs. high) & 0.000 & $3.267(1.851-5.767)$ & & 0.001 & $3.192(1.804-5.646)$ \\
Invasion depth (T1/2 vs. T3/4) & & 0.026 & $0.501(0.272-0.921)$ & & 0.314 & $1.433(0.711-2.887)$ \\
Lymph node metastasis (N0 vs. N1/2/3/X) & & 0.018 & $0.554(0.340-0.904)$ & & 0.057 & $0.272(0.071-1.041)$ \\
Distant metastasis (M0 vs. M1) & & 0.948 & $1.048(1.048-4.288)$ & & 0.633 & $0.821(0.365-1.847)$ \\
TNM stage (I/II vs. III/IV) & & 0.005 & $2.150(1.258-3.674)$ & & 0.007 & $2.084(1.217-3.569)$ \\
Histological type (invasive AC vs. variant invasive AC) & 0.627 & $1.215(0.554-2.663)$ & & 0.431 & $0.502(0.090-2.791)$ \\
\hline
\end{tabular}

AC, adenocarcinoma; HR, hazard ratio; CI, confidence interval; MCT-4, monocarboxylate transporter 4.

A
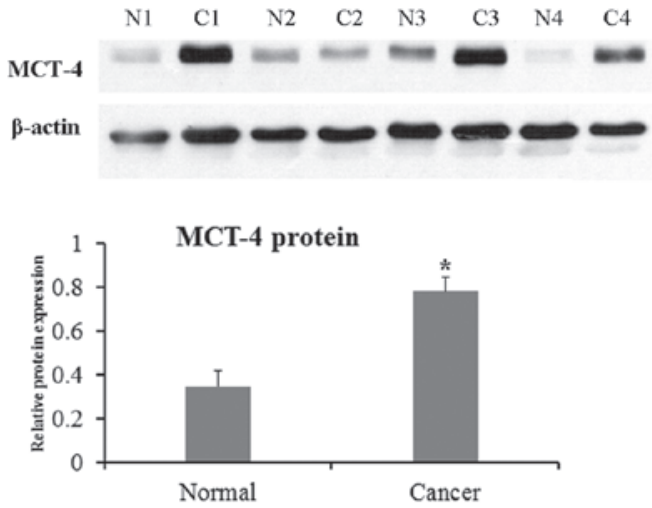

B

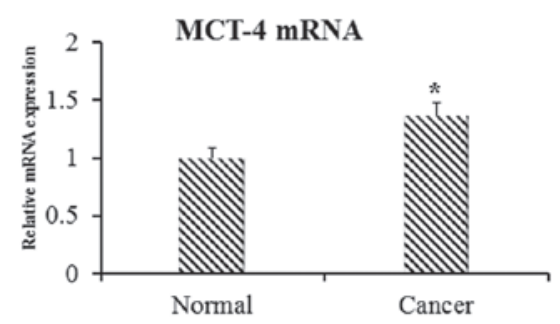

Figure 4. Expression of MCT-4 protein and mRNA in the human lung ACs and corresponding normal lung tissues. An increased expression of MCT-4 protein and mRNA in the lung ACs was detected by (A) western blotting, of which representative images are shown, and (B) reverse transcription-quantitative polymerase chain reaction, compared with normal lung tissues $(n=30$, $\left.{ }^{*} \mathrm{P}<0.05\right)$. MCT-4, monocarboxylate transporter 4; AC, adenocarcinoma; N, normal; C, cancer.

\section{Discussion}

In the present study, it was revealed that MCT-4 immunoreactivity was predominantly observed at the cell membrane and cytoplasm of the tumor cells, as well as in the alveolar macrophages and bronchial epithelium. Additionally, it was mildly expressed in stromal cells of lung AC tissues and negative in alveolar epithelial cells. The results suggested that MCT-4 protein and mRNA level were significantly increased in AC tissue, compared with corresponding normal lung tissues.
High MCT-4 level was also associated with an advanced (T3/4) depth of invasion, and high expression in tumor cells predicted poor prognosis. Based on this data, MCT- 4 may be a candidate therapeutic target for lung AC patients.

Lung AC is one of the most deadly and widespread diseases and remains a significant concern for public health (1). In recent years, the clinical and prognostic value of MCT-4 has been identified for certain types of cancer (23-27), and the tumor-promoting role of high MCT-4 expression has also been clarified $(24,26,27,34)$. Although experimental evidence appears to indicate that MCTs are potential targets for cancer therapy $(35,36)$, the function of these membrane proteins in lung AC is not understood clearly. Therefore, the present study attempted to clarify the effect of MCT-4 on prognosis in lung AC. For this purpose, the expression of MCT-4 in lung ACs and corresponding normal lung tissues was analyzed.

In the present study, $17.1 \%$ (25/146) of lung AC cases exhibited high MCT-4 expression, which was lower than a previous report in which $48.78 \%$ (20/41) of lung AC cases exhibited high MCT-4 expression (34). This discrepancy may be explained by different IHC scoring methods. Positive rates of MCT-4 protein in lung AC samples were increased, compared to normal lung tissues in the present study, which demonstrated that there is a different mechanism for metabolism between normal lung and lung AC cells. Western blot results confirmed the specificity of the MCT-4 antibodies, providing further evidence for the validity of the data of the present study. It was also identified that high MCT-4 level is associated with an advanced depth of invasion (T3/4) and that a high expression level of MCT-4 was an independent prognostic marker for a poor prognosis in lung AC. Another study has reported that high GLUT1 and MCT-4 expression levels are closely associated with poor disease-specific survival (DSS) time in lung ACs, but not in lung squamous cell carcinomas (34). In another study, MCT-4 expression in cancer cells is significantly associated with a poor DSS time in NSCLC (37). The aforementioned results imply that MCT-4 may be a candidate therapeutic target for the treatment of patients with lung AC.

MCT-4 mediates the efflux of lactate, which is produced during glycolysis, across cell membranes (38). A previous study demonstrated that cells that expressed MCT-4 exhibit 
increased invasive behavior compared with cells that no express MCT-4 (39). Tumors consist of stromal cells and tumor cells; the former may constitute $>50 \%$ of the tumor mass. There is evidence to suggest that stromal cells serve an important function in tumor metastasis and invasion through tumor-stroma interactions (40). It has recently reported that stromal MCT-4 has promise as a biomarker for predicting the prognosis of patients with gastric cancer (41). MCT-4 expression in stroma is also independently associated with a worse biochemical failure-free survival time in prostate cancer (42). In the present study, weak MCT-4 expression was detected in the stroma of only a small number of lung AC samples; it may be difficult to meaningfully analyze this further from the low number of samples. However, in a previously study, decreased expression of MCT-1 in cancer cells, decreased expression of stromal MCT-2 and -3 , and increased expression of stromal MCT-1 have been identified as significant independent prognostic markers for poor DSS in NSCLC, although no significant association is observed between stromal MCT-4 expression and DSS time in NSCLC (37). Thus, many aspects of the association between stromal MCT-4 expression and the invasive activity of lung AC cells have yet to be explored.

In summary, high expression of MCT-4 is associated with a high depth of invasion (T3/4) of lung ACs. Expression of MCT-4 protein in tumor cells predicts a poor prognosis for patients with lung AC. Multivariate analysis demonstrated that high expression of MCT-4 is an independent poor prognostic predictor for lung AC patients. The results suggest a novel biomarker for lung AC, and are in agreement with previous data indicating that MCT-4 may mediate the transport of lactate from tumor cells to the extracellular matrix $(12,43)$. The transport of lactate, in addition to protons exported by proton pumps, increase the acidity of the extracellular environment (12). Consequently, a number of cytokines from the extracellular membrane are activated via MMPs or other proteases. In turn, these cytokines mediate neovascularization, cell survival and epithelial-mesenchymal transition, to assist the survival of cancer cells (44). Furthermore, patients with lung AC with high MCT-4 expression may benefit from MCT-4 inhibitors or other novel treatment approaches based on MCT-4 expression. It is necessary to conduct further studies and investigate the molecular mechanisms associated with MCT-4 expression to develop biomarkers and prospective clinical trials to fully explore the significance of MCT-4 level in lung $\mathrm{AC}$ prognosis.

\section{Acknowledgements}

The present study was supported by grants from the National Natural Science Foundation of China (grant no. 30900652) and Shenzhen R\&D Technology Research Projects (grant no. JCYJ20140416122812024).

\section{References}

1. Siegel RL, Miller KD and Jemal A: Cancer statistics, 2015. CA A Cancer J Clin 65: 5-29, 2015.

2. Thomas A, Liu SV, Subramaniam DS and Giaccone G: Refining the treatment of NSCLC according to histological and molecular subtypes. Nat Rev Clin Oncol 12: 511-526, 2015.
3. Sica G, Yoshizawa A, Sima CS, Azzoli CG, Downey RJ, Rusch VW, Travis WD and Moreira A: A grading system of lung adenocarcinomas based on histologic pattern is predictive of disease recurrence in stage I tumors. Am J Surg Patho 34: $1155-1162,2010$.

4. Alberg AJ, Ford JG and Samet JM; American College of Chest Physicians: Epidemiology of lung cancer: ACCP evidence-based clinical practice guidelines. Chest 132: 29S-55S, 2007.

5. Travis WD, Brambilla E, Noguchi M, Nicholson AG, Geisinger K, Yatabe Y, Powell CA, Beer D, Riely G, Garg K, et al: International Association for the Study of Lung Cancer/American Thoracic Society/European Respiratory Society: International multidisciplinary classification of lung adenocarcinoma: executive summary. Proc Am Thorac Soc 8: 381-385, 2011

6. Sterlacci W, Savic S, Schmid T, Oberaigner W, Auberger J, Fiegl M and Tzankov A: Tissue-sparing application of the newly proposed IASLC/ATS/ERS classification of adenocarcinoma of the lung shows practical diagnostic and prognostic impact. Am J Clin Pathol 137: 946-956, 2012.

7. Bissell MJ and Radisky D: Putting tumours in context. Nat Rev Cancer 1: 46-54, 2001.

8. Mueller MM and Fusenig NE: Friends or foes-bipolar effects of the tumour stroma in cancer. Nat Rev Cancer 4: 839-849, 2004.

9. Dvorak HF, Weaver VM, T1sty TD and Bergers G: Tumor microenvironment and progression. J Surg Oncol 103: 468-474, 2011.

10. Vaupel P, Kallinowski F and Okunieff P: Blood flow, oxygen and nutrient supply and metabolic microenvironment of human tumors: A review. Cancer Res 49: 6449-6465, 1989.

11. Izumi H, Torigoe $\mathrm{T}$, Ishiguchi $\mathrm{H}$, Uramoto $\mathrm{H}$, Yoshida $\mathrm{Y}$, Tanabe M, Ise T, Murakami T, Yoshida T, Nomoto $M$ and Kohno K: Cellular $\mathrm{pH}$ regulators: Potentially promising molecular targets for cancer chemotherapy. Cancer Treat Rev 29: 541-549, 2003.

12. Pinheiro C, Longatto-Filho A, Azevedo-Silva J, Casal M, Schmitt FC and Baltazar F: Role of monocarboxylate transporters in human cancers: State of the art. J Bioenerg Biomembr 44: 127-139, 2012.

13. Halestrap AP and Price NT: The proton-linked monocarboxylate transporter (MCT) family: Structure, function and regulation. Biochem J 343: 281-299, 1999.

14. Broer S, Bröer A, Schneider H, Stegen C, Halestrap A and Deitmer J: Characterization of the high-affinity monocarboxylate transporter MCT2 in Xenopus laevis oocytes. Biochem J 341: 529-535, 1999 .

15. Grollman EF, Philp NJ, McPhie P, Ward RD and Sauer B: Determination of transport kinetics of chick MCT3 monocarboxylate transporter from retinal pigment epithelium by expression in genetically modified yeast. Biochemistry 39: 9351-9357, 2000.

16. Dimmer KS, Friedrich B, Lang F, Deitmer JW and Bröer S: The low-affinity monocarboxylate transporter MCT4 is adapted to the export of lactate in highly glycolytic cells. Biochem J 350: 219-227, 2000.

17. Fox JEM, Meredith D and Halestrap AP: Characterisation of human monocarboxylate transporter 4 substantiates its role in lactic acid efflux from skeletal muscle. J Physiol 529: 285-293, 2000.

18. Koukourakis MI, Giatromanolaki A, Harris AL and Sivridis E: Comparison of metabolic pathways between cancer cells and stromal cells in colorectal carcinomas: A metabolic survival role for tumor-associated stroma. Cancer Res 66: 632-637, 2006.

19. Lin RY, Vera JC, Chaganti RS and Golde DW: Human monocarboxylate transporter 2 (MCT2) is a high affinity pyruvate transporter. J Biol Chem 273: 28959-28965, 1998.

20. Lambert DW, Wood IS, Ellis A and Shirazi-Beechey S: Molecular changes in the expression of human colonic nutrient transporters during the transition from normality to malignancy. Br J Cancer 86: 1262-1269, 2002.

21. Pinheiro C, Longatto-Filho A, Scapulatempo C, Ferreira L, Martins S, Pellerin L, Rodrigues M, Alves VA, Schmitt F and Baltazar F: Increased expression of monocarboxylate transporters 1, 2 and 4 in colorectal carcinomas. Virchows Archiv 452: 139-146, 2008.

22. Juel C and Halestrap AP: Lactate transport in skeletal muscle-role and regulation of the monocarboxylate transporter. J Physiol 517: 633-642, 1999

23. Pinheiro C, Reis RM, Ricardo S, Longatto-Filho A, Schmitt F and Baltazar F: Expression of monocarboxylate transporters 1, 2 and 4 in human tumours and their association with CD147 and CD44. J Biomed Biotechnol 2010: 427694, 2010. 
24. Nakayama Y, Torigoe T, Inoue Y, Minagawa N, Izumi H, Kohno K and Yamaguchi K: Prognostic significance of monocarboxylate transporter 4 expression in patients with colorectal cancer. Exp Ther Med 3: 25-30, 2012.

25. Kim MJ, Kim DH, Jung WH and Koo JS: Expression of metabolism-related proteins in triple-negative breast cancer. Int J Clin Exp Pathol 7: 301-312, 2013.

26. Zhu J, Wu YN, Zhang W, Zhang XM, Ding X, Li HQ, Geng M, Xie ZQ and Wu HM: Monocarboxylate transporter 4 facilitates cell proliferation and migration and is associated with poor prognosis in oral squamous cell carcinoma patients. PLoS One 9: e87904, 2014.

27. Pértega-Gomes N, Vizcaíno JR, Miranda-Gonçalves V, Pinheiro C, Silva J, Pereira H, Monteiro P, Henrique RM, Reis RM, Lopes C and Baltazar F: Monocarboxylate transporter 4 (MCT4) and CD147 overexpression is associated with poor prognosis in prostate cancer. BMC Cancer 11: 312, 2011.

28. Sobin LH, Gospodarowicz MK and Wittekind C: International Union against Cancer. TNM classification of malignant tumours 7th edition. Chichester, Hoboken NJ: Wiley-Blackwell, 2010.

29. Kononen J, Bubendorf L, Kallionimeni A, Bärlund M Schraml P, Leighton S, Torhorst J, Mihatsch MJ, Sauter G and Kallioniemi OP: Tissue microarrays for high-throughput molecular profiling of tumor specimens. Nat Med 4: 844-847, 1998.

30. Li M, Chen H, Diao L, Zhang Y, Xia C and Yang F: Caveolin-1 and VEGF-C promote lymph node metastasis in the absence of intratumoral lymphangiogenesis in non-small cell lung cancer. Tumori 96: 734, 2010

31. Chen H, Xue J, Zhang Y, Zhu X, Gao J and Yu B: Comparison of quantum dots immunofluorescence histochemistry and conventional immunohistochemistry for the detection of caveolin-1 and PCNA in the lung cancer tissue microarray. J Mol Histol 40 : 261-268, 2009.

32. Zhao X, He Y, Gao J, Fan L, Li Z, Yang G and Chen H: Caveolin-1 expression level in cancer associated fibroblasts predicts outcome in gastric cancer. PLoS One 8: e59102, 2013.

33. Livak KJ and Schmittgen TD: Analysis of relative gene expression data using real-time quantitative PCR and the 2(-Delta Delta C(T)) method. Methods 25: 402-408, 2001.

34. Meijer TW, Schuurbiers OC, Kaanders JH, Looijen-Salamon MG, de Geus-Oei LF, Verhagen AF, Lok J, van der Heijden HF, Rademakers SE, Span PN and Bussink J: Differences in metabolism between adeno-and squamous cell non-small cell lung carcinomas: Spatial distribution and prognostic value of GLUT1 and MCT4. Lung Cancer 76: 316-323, 2012.

35. Mathupala SP, Parajuli P and Sloan AE: Silencing of monocarboxylate transporters via small interfering ribonucleic acid inhibits glycolysis and induces cell death in malignant glioma: An in vitro study. Neurosurgery 55: 1410-1419, 2004.
36. Sonveaux P, Végran F, Schroeder T, Wergin MC, Verrax J, Rabbani ZN, De Saedeleer CJ, Kennedy KM, Diepart C, Jordan BF, et al: Targeting lactate-fueled respiration selectively kills hypoxic tumor cells in mice. J Clin Invest 118: 3930-3942, 2008.

37. Eilertsen M, Andersen S, Al-Saad S, Kiselev Y, Donnem T, Stenvold H, Pettersen I, Al-Shibli K, Richardsen E, Busund LT and Bremnes RM: Monocarboxylate transporters 1-4 in NSCLC: MCT1 is an independent prognostic marker for survival. PLoS One 9: e105038, 2014

38. Garcia CK, Goldstein JL, Pathak RK, Anderson RG and Brown MS: Molecular characterization of a membrane transporter for lactate, pyruvate and other monocarboxylates: Implications for the Cori cycle. Cell 76: 865-873, 1994.

39. Izumi $H$, Takahashi M, Uramoto $H$, Nakayama $Y$, Oyama $T$, Wang KY, Sasaguri Y, Nishizawa $S$ and Kohno K: Monocarboxylate transporters 1 and 4 are involved in the invasion activity of human lung cancer cells. Cancer Sci 102: 1007-1013, 2011

40. Lorusso G and Rüegg C: The tumor microenvironment and its contribution to tumor evolution toward metastasis. Histochem Cell Biol 130: 1091-1103, 2008.

41. Zhao Z, Han F, He Y, Yang S, Hua L, Wu J and Zhan W: Stromal-epithelial metabolic coupling in gastric cancer: Stromal MCT4 and mitochondrial TOMM20 as poor prognostic factors. Eur J Surg Oncol 40: 1361-1368, 2014.

42. Andersen S, Solstad $\varnothing$, Moi L, Donnem T, Eilertsen M, Nordby Y, Ness N, Richardsen E, Busund LT and Bremnes RM: Organized metabolic crime in prostate cancer: The coexpression of MCT1 in tumor and MCT4 in stroma is an independent prognosticator for biochemical failure. Urol Oncol 33: 338.e9-17, 2015.

43. Sanità P, Capulli M, Teti A, Galatioto GP, Vicentini C, Chiarugi P, Bologna $\mathrm{M}$ and Angelucci A: Tumor-stroma metabolic relationship based on lactate shuttle can sustain prostate cancer progression. BMC Cancer 14: 154-167, 2014.

44. San-Millán I and Brooks GA: Reexamining cancer metabolism: Lactate production for carcinogenesis could be the purpose and explanation of the Warburg Effect. Carcinogenesis 38: 119-133, 2017. 